10.1515/ausfm-2015-0002

\title{
Intermediate Images
}

\author{
Joachim Paech \\ Professor Emeritus, University of Konstanz (Germany) \\ E-mail: jopaech@aol.com
}

Keynote talk given at the conference of ISIS (International Society for Intermedial Studies) "Rethinking Intermediality in the Digital Age" organized by the Sapientia Hungarian University of Transylvania, in Cluj-Napoca, Romania, between the $24^{\text {th }}$ and $26^{\text {th }}$ of October 2013. (The photos of Joachim Paech illustrating the article were taken by Ágnes Pethő.)
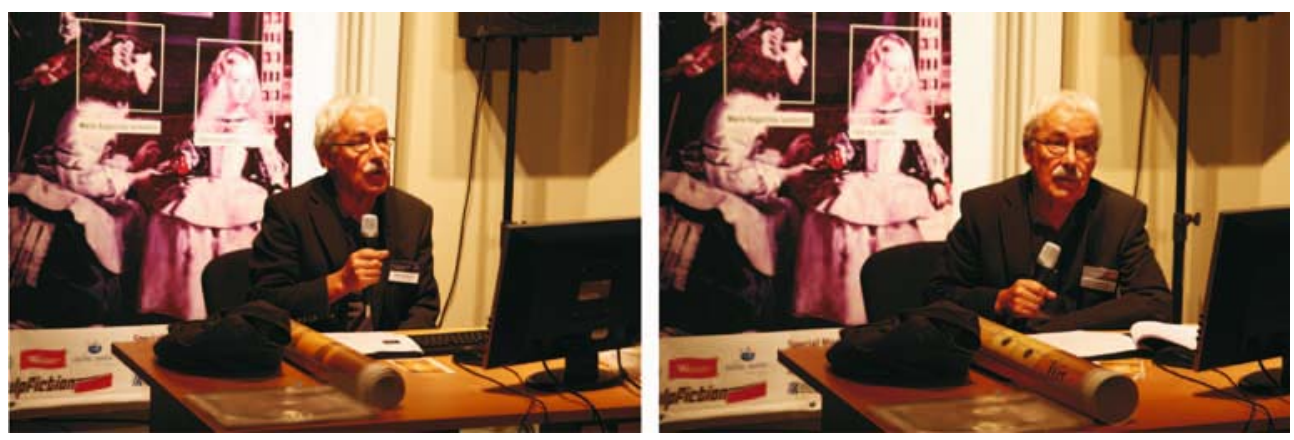

Abstract. Starting from a definition of the word 'picture' as a real-world object that shows other objects on its surface as a representation of its image, I propose that the intermediality of pictures of all kinds is only possible through their images, after they have been separated from their material basis or foundation (for example, a painting in its physical reality can never be directly connected with a movie). In all technical reproductions of images, such as printing processes, an image is taken from a negative matrix in order to realize multiple prints of the same representation. The most effective model of this procedure is photography: photographic images can easily be connected with their media forms to produce other, more complex forms, such as magazines, printed books, or films. Intermediate images in the form of matrices - sometimes transparent (e.g. in the light beam of a film projection), sometimes opaque - are required to transform one pictorial media form into another. Finally, for the digital matrix-image, there is no longer any difference between the matrix and the image: the matrix has become its own image, which can be linked to all other media forms.

Keywords: image, picture, matrix, technical reproductions of images, digital matrix image. 
At the beginning of my talk, which will deal with various aspects of pictures, I would have preferred introducing a picture that I personally like very much. Its title is Scanty Words of the Thrifty Man (Karge Worte des Sparsamen), painted by Paul Klee in 1924, oil and watercolour on paper, $45 \mathrm{~cm}$ by $29.5 \mathrm{~cm}$ [Fig. 1]. Unfortunately, the Berggruen Collection at the Staatlichen Museen zu Berlin, where the picture currently resides, refused to make the painting available for our colloquium, and therefore it must remain in its place on the museum wall. Nevertheless, although it is not the original, I can show you photographic reproductions that depict this painting by Paul Klee, but which of course cannot be the picture itself. In the following, I will refer to such reproductions as 'images' (that is, images of the original picture). Printed on paper, the poster and the postcard offered at the museum shop are colour prints featuring rather different colour tones and formats [Fig. 2]. The great number of copies of these prints is significant; in contrast, the original picture hanging in its place on the museum wall in Berlin is the only irreproducible specimen. What recurs in the prints is not the picture, but rather the image, the representative surface that obviously can be detached from the picture and reproduced in many ways with different media properties. The images on the posters and postcards, as I've already noted, are not the picture that they depict (even though we frequently make this substitution for the sake of convenience), but they signify it, in that their images refer back to the picture. They have the shape and the figure of the picture, such that they formulate the picture that they signify or represent. These images are apparently capable of multiplying themselves with different media properties. In this sense, the extreme case is the digital form of an image, which can employ any format, colour nuance, and media connection in processes of intermediality as on this page in its digitally represented combination of an image and a text.

The following considerations will address the intermediality of images. My thesis is that there cannot be an intermediality of pictures (because of their singularity and their particular media properties); however, an intermediality of images is possible. For the intermediality of images, certain requirements of the technique play a significant role; this refers to the creation of inauthenticities (uneigentliche) or quasi-pictures, which in the following analysis I will call matrices. These matrices are fundamental elements in the operation of the technical imaging process, functioning as intermediate images (ZwischenBilder) for both the production of images as well as their integration into other media processes. 


\section{Pictures}

For several reasons, this discussion about images and their intermediality presupposes an answer to the oft-repeated question, "What is a picture?" (cf. Mitchell 1990; Boehm 1994). For one thing, images are also pictures, even if they are other pictures. Second, the historical appearance (or debut) of images as the result of technical reproductive processes occurred as a specific separation (or differentiation in terms of media) within the history of pictures. And third, in our media-amnesia, we have become accustomed to calling everything that deals with representations of visuality in the broadest sense of the term 'a picture,' but which will refer to different regimes of the term. Only against the background of media differentiation does it become clear that paintings and sculptures on the one hand and metaphors, symbols, imagined or remembered pictures, or mental images on the other cannot be subsumed under the same concept of picture. Especially in their intermedia use, the media properties of pictures play the determining role in their media sphere; for this reason, the metaphoric meaning of the term picture is excluded from this discussion.

I would like to suggest the following basic definition for the word picture. The term refers to a real-world object that represents other real or unreal objects, especially in their absence, without being them (although specific restrictions might apply to abstract paintings ${ }^{1}$ ). A picture is always just a picture, no matter what it shows. The uses of pictures beyond this definition (for example, metaphoric, magical, or mystical uses) have no relation to their intrinsic properties, being the results of different attributions. Pictures as physical objects and representations are characterized by their two-sided form, whereby one side, the form, is determined by the other, the medium. Each side is echoed on the other: the medium in the figural process of its representation, and the form in the observation of the medium as a picture. The media (material) properties of the canvas and paints used in a painting or the marble of a sculpture determine the respectively represented forms; the canvas and marble are observable as forms of their materiality and become media of (aesthetic) representation only in their use as picture or sculpture. This observation of a picture as a "two-sided form" is the prerequisite for the idea that the inseparable unity that is this picture can under certain circumstances divide

1 If, as Clement Greenberg asserts, the proper subject matter of each individual art form is precisely that which is based solely on the nature of its particular medium, then for art that is its own subject, any intermedial extension is precluded. Pictures, too, are only that which they represent - namely, pictures. (Cf. Greenberg: Modernistische Malerei (255-264) and Intermedia (446-455), in Die Essenz der Moderne, 1997.) 
into two forms, one of which (the figurative representation) can be formulated anew under other media conditions. The picture stays behind (e.g. on the wall in the museum), while its image, with other media properties, can be (nearly) endlessly multiplied and connected to other media forms.

Every picture as an object of reality and - as a rule - a product of craftsmanship and artistic production is unique. Pictures are unique occurrences or occurrences of their uniqueness. The artist's signature marks the uniqueness of a visual work of art by reference to its author. A specific picture has a specific place, even though it can be moved (or transported) between sites. Catalogues classify pictures according to their locations in galleries or museums. Pictures themselves are not reproducible. The copies of a picture are new pictures, whose reference is their model; they are forgeries if they seek to take the place of their model. Copying and forgery do not nullify the uniqueness of the models, as long as the new works are recognizable as copies; otherwise, they become another original picture.

Pictures as unique objects in our physical reality that exhibit specific media (material) properties cannot be connected in processes of intermediality with other media forms. In other words, the representation of a painting (e.g. in a book or a film) by the painting itself is not possible.

\section{Images}

The intermedia reproduction of a picture in another media connection presupposes the fact that the picture is generally reproducible and exhibits media properties that allow it to connect with other media surroundings. Images are media forms generated by pictures that can be removed from their source medium and connected to other media in which they are limitlessly reproducible. An image refers to its media origin (i.e., the original medium) as a picture by repeating its image and conveying traces of its media properties in its form. Images thus 'formulate' the picture by using its image in other media contexts.

Along with their ability to be endlessly duplicated, the process by which images are separated from their pictorial origins or models and become independent artistic entities is at the core of the history of the technical production of pictures (actually the production of images, to use this discussion's definitions). Initially, this production was not focused on the repetition of (artisanal or artistic) pictures by means of their reproduction. Early technical representations are basically prints from matrices with various media properties, such as stone, metal, wood, or (for photographs) glass and celluloid. Often, the plate of the matrix was produced 
as a work of art by a master craftsman; however, the matrix was not the intended final picture, but rather the images or prints that were produced using a simple technical or mechanical process. When the printing process was finished and the desired or technically possible quantity of prints had been produced, the matrix could be destroyed (for example, if the edition of the prints was intended to be limited). In some cases, the limitation of this duplication has given the prints some properties of the original, but one never obtains original pictures from an image. Even valuable wood or copperplate engravings (e.g. from Dürer's time) are multiple images of their matrix in the printing process. A similar situation applies to photographs; even in the case of a restricted edition of prints by the artist, these prints have their origin in a matrix and in its ability to endlessly reproduce the same image.

The technical printing method shows how the image frees itself from its matrix, which as a negative form can transfer its media properties through printing onto another medium (paper) that reproduces the media form of the matrix (but not its medium). The medium can be destroyed, but its form has been transferred by means of the printing process and thus it continues as a form in another medium (paper) [Figs. 3-5].

The intermediality of images is made possible by the process of transformation that occurs between the matrix and the image, whereby the represented form is transferred between a negative source (the matrix) and a (reproducible) positive image. This new trans-form is capable of connection to various other media forms. ${ }^{2}$ The technical reproduction of original paintings (or sculptures) assumes that first a matrix can be produced; then, using this matrix, the picture can be reproduced in the new media form of its image. This is the historical achievement of the photograph, which has utilized its matrix to transform the world's objects (including physical pictures) into a world of image streams.

Walter Benjamin has described this process of transformation with two concepts that can clarify the process from different sides. First, in our cultural history, technical reproduction and duplication has always been connected with the production of a work of art with the help of a matrix - with casting moulds, punches, or blocks - while unique works of art have generally been irreproducible. In Benjamin's ontological understanding of photography, the photograph, the output of the most advanced reproductive technology, directly

2 According to Luhmann connectivity refers to the "feasibility of other possibilities." Symbolic characters (e.g. letters) feature high connectivity; iconic characters (e.g. pictures) have lower connectivity (cf. Luhmann 1987). 
repeats the object of reference in its image; it thus corresponds to the "the urge [...] to get hold of an object in very close proximity by way of its picture, or better its image, its reproduction [Benjamin's distinction]. Unmistakably, reproductions such as those offered by picture magazines and newsreels differ from pictures" (Benjamin 1963, 18-19). Common to all reproductive technologies is the fact that they allow multiple images of their models, as alike as fingerprints; however, these images lack the authenticity of the unique picture, which is why Benjamin insists that they are merely images.

The second concept that Benjamin proposes to clarify the process behind the history of reproductions is translation. Benjamin describes translation as a form $^{3}$ that is already contained within the original and that serves its survival, in that it refers back to the original, over and over again. This idea of translation can be applied to literary works, which have been basically reproducible since Gutenberg, but it can also be related to other media forms - especially nowadays, when literary translations increasingly include transformations into other media forms, such as films, television series, etc. The translation as a form (cf. Paech 2010), i.e. the general translatability, is what controls or formulates the media transformation in the reproductive process. The photographic reproduction is also a translation, not of any presumed reality, but rather of the media form of the matrix, a negative form, which produces by means of light prints (positive) images of the matrix and the form of its translation.

Forms of a translation ${ }^{4}$ are elements of all technical reproductive processes that operate in the transformation between the matrix and the images that it formulates. They are intermediate images or quasi-images that transport the forms of media properties as well as elements of their figuration, which they realize intermedially.

How are these intermediate or quasi-images that are defined by their function in intermedia processes observable? The matrices themselves disappear, or else these intermediate forms are media forms that are completely absorbed by their function in intermedia processes. Basically, these media are exclusively observable in the forms that they generate. ${ }^{5}$ They themselves as media can be

3 "Translation is a form. In order to grasp it as such, we have to go back to the original. For in it lies translation's law, decreed as the original's translatability." (In original: "Übersetzung ist eine Form. Sie als solche zu erfassen, gilt es zurückzugehen auf das Original. Denn in ihm liegt deren Gesetz als in dessen Ubersetzbarkeit beschlossen.” Benjamin 1980, 50.)

4 McLuhan speaks about "media as translators" (1968, 56-61), if something is "translated or carried across from one kind of material form into another" $(1968,58)$.

5 Media generate forms, which in turn as media generate themselves as new forms, 
observed only in forms that become transparent through their function - that is, they are observable through their effects, while remaining invisible as media in the blind spot of their perception - or in opaque forms that obstruct and possibly nullify their media function. In this way, the medium of the images becomes an image of its medium.

\section{Intermediate Images}

In his media phenomenology, Emmanuel Alloa (2011) takes as a starting point Aristotle's question of how the object of perception becomes the perceived object in the act of seeing. It is impossible for the object in its physical concreteness to penetrate the eye and the perceiving consciousness; thus, in order for an object to be seen, there must be a mediation by something between object and eye that neither shares the material properties of the object nor belongs to the eye - nor is it, generally speaking, a thing. This "between," which Aristotle calls metaxy (Mahr 2003), is purely a medium of appearance, in that it enables the object in the act of perception to appear. It transfers the object as a form and in this manner informs the viewer's perception. "The metaxy must let the form pass; however, conversely, the form passes only by means of the metaxy. [...] As a medium of appearance, this metaxy or hymen (after Thomas Aquinas) allows its own appearance to be eclipsed, as it were, becoming translucent" (Alloa 2011, 132). The medium of perception disappears with that which it brings to light as the perceived form. Its transparency (Diaphanie) turns into opacity when this medium itself appears as a form and becomes performatively descriptive.

etc.; this means that media appear in the guise of forms, and that they can only be observed in the forms that they generate: as a mediatized form and as the form of their medium, a consequence of their basic reflexivity. Media are not objects, but rather conditions or possibilities of their formative processes and their observation. This enables the "realization that the distinction between medium and form is itself a form - a form with two sides, one side of which (the form) contains itself." This signifies "that the distinction circles back to itself; it recurs in itself on one of its sides" (Luhmann 1995, 169). The difficulties of this paradoxical construction of the relationship between medium and form can be mitigated by referring to the side in which the form is repeated as the 'figure' and the process of its formulation as 'figuration.' Media formative processes can thus become (aesthetically) concrete by the very figuration of their technique. Intermediality as a technique can therefore be described as a certain figure (figuration) of a media formative process, namely as the repetition or rewriting of a medium as a form in the form of (another) media, in which the process of intermediality 'figures,' thus becoming concrete and reflexive with respect to itself, as the technique indicates. Media are not observable as objects, and intermediality cannot be described as an objectifiable fact; rather, they are processes that leave observable traces. 
With the development of the geometrical-mathematical construction of perception (i.e. in perspective modelling in Renaissance paintings), the form through which perception is transmitted was attributed a particular significance for the representation of seeing. The originally diaphanous (transparent) medium of transmission, the metaxy between object and eye (or consciousness), now becomes the visible form of the formulation of visibility, more or less displacing the mediated object. The medium thus changes from one of transparency (Diaphanie) to one of opacity.

In Dürer's Unterweysung der Messung (Instruction in Measurement, 1538) [Fig. 6], a transparent cloth or velum (cf. Endres-Wittmann-Wolf 2005) is stretched between the (motionless!) object of the perception and the perceiving eye. Visual lines connect every point of the object to the eye of the observer or artist. The positions at which they cut through this velum (or are cut by the velum) are conscientiously marked until an image of the object as it appears to the eye is generated on the cloth. No longer invisible (diaphanous) but instead an increasingly opaque medium of perception, it should enable the perception of the object to appear as the image of its perception, which can serve as a matrix for additional images. From the outset, it has its own (media) form, a network structure or grid (cf. Krauss 1981; Dyett 2013) into which another perceived form of the object is inscribed, until it or its own image is hidden by the object of the perception. From this matrix, it is possible to obtain further images, which can also be repeated in other media contexts. What comes into being here is an intermediate image whose origin reveals the transition from the transparent (diaphanous) medium of the appearance to the opacity of its own image. This interchange between transparency and imagery (representation) recurs throughout the history of technical reproductions and intermedia images, becoming increasingly more important.

How, then, does the photograph operate, this technically reproductive medium that was the first to putatively render superfluous the intervention of the human hand in the image production process (according to Benjamin)? The photograph was invented with the intention of accelerating traditional printing methods by means of the exposure of printing plates. Even today, photographs are referred to as prints. (Here, we are speaking of photographs in the modern sense, following the introduction of the negative vs. positive procedure of Fox Talbot's Calotype.) In the camera obscura of the camera, a photochemically treated glass surface is exposed to light through an objective lens. The negative thus produced can be used afterwards as a matrix for light prints on paper. Photographs are thus 
images taken from a matrix, from which an arbitrary number of photo prints or proofs can be made. With regard to this media constellation, it is difficult to speak of photographs in the ontological understanding as direct fingerprints or traces of reality. ${ }^{6}$ A photograph is the image of its matrix; it is that which appears between a (photographic) matrix (on glass, film, etc.) and its imprint, which in this form can be endlessly repeated. This operative space is open to interventions and manipulations in the image process.

From the outset, the common usability or ubiquitous accessibility of the new technical images enabled by photography was one of the technique's most outstanding characteristic features. In different dimensions, on different backings, etc., these photographic images could be inserted in complete editions of books, for example. In this cumulative sense, photographs were not yet an intermedia part of books (or the literature); up to the end of the nineteenth century, woodcuts (often based on a photograph) were still preferred to photographs because they could be integrated into a text and be printed together with it. Ultimately, the development of the raster process enabled the direct connection of photographs with the surrounding text, using a point structure shared by both (a technique used at first for illustrated magazines). An exemplary intermedia procedure! In this process, the photograph is dissolved into a network of points whose size or density dictates the sharpness or resolution of the representation, and whose variations in brightness (greyscale values) results in the shading of surfaces and contours. Whereas the irregular granularity of the photochemical surface is a media property of the photographic image, the additional raster enables the picture to be connected to the point construction of the printed text. The raster is a form of translation - here, the translation of a text structure into a picture structure for the direct connection of the two; it is the use of a velum in the opposite direction, now not for the purpose of constructing an image, but rather for the disintegration of the image into the surrounding text. This image printed in halftone can again serve as a matrix for the rotary press and the printing of text/image combinations.

To reiterate, it is impossible to connect a picture in its physical state with, for example, a book through an intermedia procedure. The separation of the image from its surface and the associated possibilities for different media representations and resolutions are what enable an image to be connected with

6 The photograms of Man Ray are no exception, as they themselves represent the matrix with their primary impression of light, from which further images can be made in the form of photographs. 
other media surroundings. The raster matrix transforms an image into a text that can be printed and read together with the surrounding text: this picture has actually become a media component of another medium, namely the book (or the magazine, etc.).

Aristotle assumed that between objects in reality and their perception there existed a certain metaxy, a necessary medium that could transport the appearance of a thing to the eye or the consciousness while itself remaining invisible, transparent, or diaphanous. Even without its own form, it formulates other forms, allowing them to be perceived. With the velum, this medium has taken a form: the network or grid structure of a cloth, the form of which is increasingly covered by what it formulates (the perceived object). Thereby, it becomes the matrix of its image, which could be removed from the context of its origin and replicated. For Aristotle, such an appearance always maintained the directness of its link with the perceived object by means of the transparent or diaphanous nature of its medium. The opacity of the velum, in contrast, has blocked the origin of the appearance with its image. The matrix has thus become a machine for "secondhand" appearances of real-world objects and a reality that becomes increasingly invisible behind the flow of images.

At this point, I would like to refer to the distinction that was introduced by Bolter and Grusin (1998) into the discussion of intermediality, which they call remediation. Re-mediation (like our intermediality) is defined as the repetition of a medium as a form in another medium, a form that demonstrates two tendencies. The first, immediacy, refers to the connection of media forms that maintains the transparency (diaphanous nature) of the medium of their connection; in the extreme case, this produces the illusion of a second nature, as can be seen in the representation of immersive rooms - i.e., images that seem to be penetrable, an effect that grew more popular with the advent of cinema. Hypermediacy in intermedia procedures means that the process of media formation itself is observable: an accumulation of various media forms leads to a clustering in close proximity or an overlapping of elements that interact, often without being transparent to each other. The immediacy of a Renaissance painting is based on its perspective construction, which guides the viewer's gaze into the depth of the represented space; when the grid of the geometrical construction of the space is superimposed, the result is hypermediacy. The addition of the intermediate image of the matrix disturbs the painting's illusionary depth of space; the image's visibility underneath the grid of lines is threatened, and a new hypermedia aesthetics of geometrical iconicity is generated [Fig. 7]. 
The complexity of the play between transparency (diaphanie) and opacity in the appearance of the image becomes evident with the modern translucent pictures provided by photographs, slides (cf. Dilly 1975 and 1996; Wenk 1999; Nelson 2000), and film images. In these cases, the matrix in the form of a slide or diapositive transmits (via its projection onto a screen) its image as a light print, enabling its appearance at a new location. The light assumes the form (or information) of the matrix, removing the image and invisibly transporting its form to the screen, where it (as an immaterial image) becomes visible or appears. The matrix is left behind (in the projector) and can be forgotten (often hidden behind a wall); the significant event is the appearance of the image. Between the screened matrix of the slide and the projected image, a space of transformation is bridged in which the transparent (diaphanous) intermediate image is transported as pure light-based information or form to the screen upon which it appears. ${ }^{7}$ In fact, the image can be made visible at any point along the projection beam ${ }^{8}$ if the transparency (diaphanie) of the intermediate image is disturbed by an opaque medium or interrupted by an opaque body. Clearly, the projected light contains the intermediate image as a transparent (diaphanous) form until it is made visible by the intervention of an opaque medium.

A film projection is nothing more than slides projected 24 times per second. The matrix of the filmstrip projects a series of frames that appear on the projection screen as a single moving picture. Their figurative difference within a coded margin allows the illusion of movement in the cinematic moving picture (without this difference, no movement becomes visible, despite the continued projection). The individual frames are projected on top of one another, as in a palimpsest; ${ }^{9}$ their transparency allows them to blend into one another, and the differences between them are seen as movement [Fig. 8].

In the beam of light from the projector to the screen, they are mere forms, transparent (diaphanous) intermediate images, metaxy that are condensed only on the opaque screen (or any intervening body) into a single moving picture. The visible moving picture on the screen owes its existence to a disturbance (cf. Jäger 2004) in the transparency (diaphanie) of the intermediate images in the light

$7 \quad$ Even the electric light, as "pure information without any content that could detract from its capacities for transformation and information," represents "a complete change" (McLuhan 1968, 62).

8 Anthony McCall gives the projection beam itself a form in his installations Line Describing a Cone (1973) and Five Minutes of Pure Sculpture (Berlin, 2012).

9 One can also refer to the moving image as a composite image of pictures with a certain family resemblance (e.g. different faces superimposed upon one another, the sequence of which appears as movement). 
beam after they have been detached from the matrix, at 24 times per second. This disturbance, which allows the intermediate images to become visible, can take place anywhere in the beam of light.

This becomes clear, for example, in Roberto Rossellini's short film Chastity (Illibatezza, 1963) where he uses this idea of interference in the film projection to emphasize the disturbance in the psychic projection of his hero. Chastity tells the story of an American who falls in love with a stewardess, whom he records with his film camera during a layover in Bangkok. Because she avoids him, he must be content to meet her in the form of these filmed pictures, which he projects in his hotel room. He positions himself in the projection beam, using himself as the screen and attempting to unite with the object of his desire meanwhile making her image, which he embodies, appear on his body between the projector and the screen.

\section{Digital Matrix Images}

I turn once again back to Aristotle. To the ancient philosopher, for an object to be able to appear, it was essential that the substance of the object be realized as a mere possibility in light of its form or shape. The form of the thing is that which is real; its substance (materiality) is a mere possibility. It is a question of the lighting that allows forms to become detached from their objects and appear as they are. Even today, the entire analogue world of pictures and images is a world of appearances whose forms have left behind the things that they formulate. Their medium is the light (Blumenberg, 1957) that illuminates the objects and projects their forms. In my opinion, this ancient model of making the world appear has returned in the cinematographic process. A great deal has changed in media history during recent years, but "it is still the light - whether it comes [for Aristotle] from the sun, an electric lamp or a videoscreen - which is the origin of all pictures and representations which presents and explains the world to us. Without light, no picture" (Couchot 1987, 115). Between the material world and the human eye, light - itself without form - shows us objects by their forms, transmitting them to our consciousness. In the space between the film projector and the screen, it is light that transports the forms of the matrix and the virtual intermediate images, and then renders them visible on the screen. Without light, no film.

The French new media scholar Edmond Couchot claims that the evolution of the computer and digital data processing has allowed the development of a "new kind of picture that no longer owes anything to light, at least not in its 
production: these are the new synthetic or numerical pictures. [...] In its creation, the synthetic picture is completely calculated by the computer" $(1987,116)$. This also applies to the light in such pictures, which as an algorithmically programmed effect forms an element of the figurative surface. Lighting here detaches no forms from objects in order to transmit their appearances; rather, it is itself a programmable form that can be distributed in a few points or extensively on the picture's surface. This picture does not require the constitutive differences that formerly separated the picture from the image and the image from its matrix. It was these differences in media forms that enabled the integration of other such forms through intermedia operations. The digital or synthetic picture no longer differentiates an image from its matrix, but it is itself a matrix image (Couchot 1987, 116). It is its matrix as a picture.

The representation of this matrix image is often hard to distinguish from photographs, although it gives itself away through the depiction of "impossible" points of view and unreal objects. The matrix image does not organize processes of intermediality in the way that films do (as a combination of photographic images, sounds, writing, visual, and narrative structures, etc.); rather, it is from the start a virtual intermedia construction of media forms that it melds with its own universal form of the computer medium. Because these synthetic pictures can presuppose no true referential reality and also claim no substantial reality for themselves, the performative data processing deals only with pure forms and their algorithmic relations in a defined pixel space. If analogue photographs become the basis for the digital representation of objects, for example, for the "picture-based modelling" (Flückiger 2008, 51) of a three-dimensional data space, then two different media forms must be reduced to a common denominator in the algorithmic calculation. Sounds and colours are media forms that are not formulated additively, as in analogue films, but instead as media forms that are algorithmically broken down and directly tied together with data from other media forms.

Because the matrix image no longer recognizes the constitutive difference between picture and image - or the object, its transformation, and the form of its appearance - there are no intermediate images in which the transformation operates either transparently (diaphanously) or opaquely to realize connections to other media forms. By means of digital compositing, point for point, pixel for pixel, other media forms are inserted into the actual matrix image as they are substituted (in coding procedures such as chroma keying) by these forms. Computer-generated representations themselves also use grid structures in a network for the arrangement of pixels in the picture space or in the development, 
for example, of polygon structures for the modelling of three-dimensional bodies. In every phase, such grids are components of the programmed picture process itself, rather than individual media forms added to supplement the (analogue) perspective construction that will disappear after contributing their spatial effect. A grid of polygons is no 'velum' that can be withdrawn so that the completed picture appears behind it. It is the picture itself [Figs. 12-13].

The intermediality of digital matrix pictures takes place as a combinatorics of coded data complexes that represent different media forms but nevertheless originate from the same media form of the computer. Many concepts left over from the analogue era have lost their meaning in digital procedures because these procedures are no longer defined based on media differences. If they are still addressed as normal pictures or images as usual it is also because digital pictures can appear to be analogue pictures without actually being them. Nevertheless, the appearance of their forms is a programmed pretence of the exclusive reality of the data stream that universally established them as nothing but visual effects (Flückiger 2008). Or, in the words of Morpheus in answer to Neo's question: "What is the Matrix? Control. The Matrix is a computer-generated dream world built to keep us under control." And: "The Matrix is everywhere. It is all around us, even now in this very room. You can see it when you look out your window, or when you turn on your television. You can feel it when you go to work, when you go to church, when you pay your taxes. It is the world that has been pulled over your eyes to blind you from the truth. [...] Unfortunately, no one can be told what the Matrix is. You have to see it for yourself." In the Wachowskis' ${ }^{10}$ film, the machines control humanity, a world of people who experience a computergenerated false world as their augmented reality. Those who belong to it cannot make a distinction between truth and the make-believe of the programmed matrix. Their matrix has ceased to be a picture; it has become - only in the film of the same name? - the entirety of the perceived reality.

10 Andy and Larry/Lana Wachowski: The Matrix (1999). 


\section{References}

Alloa, Emmanuel. 2011. Das durchscheinende Bild. Konturen einer medialen Phänomenologie [The Transparent Image. Contours of a Medial Phenomenology]. Zürich: Diaphanes.

Benjamin, Walter. 1963. Das Kunstwerk im Zeitalter seiner technischen Reproduzierbarkeit [The Work of Art in the Age of Mechanical Reproduction]. Frankfurt am Main: Suhrkamp.

Benjamin, Walter. 1980. Die Aufgabe des Übersetzers [The Translator's Task]. In Illuminationen. Ausgewählte Schriften [Illuminations. Selected Writings]. Frankfurt am Main: Suhrkamp.

Blumenberg, Hans. 1957. Licht als Metapher der Wahrheit [Light as the Metaphor of Truth]. Studium Generale vol. 10 no. 7: 432-447.

Boehm, Gottfried. 1994. Was ist ein Bild? [What is an Image?] München: Fink. Bolter, Jay David and Richard Grusin. 1998. Remediation: Understanding New Media. MIT Press: Cambridge, Massachusetts.

Couchot, Edmond. 1987. Synthèse et simulation: l'autre image [Synthesis and Simulation: the Other Image]. Hors Cadre no. 6: 115-132.

Heinrich Dilly. 1975. Lichtbildprojektion - Prothese der Kunstbetrachtung [Light Image Projection - Prosthesis for Viewing Art]. In Kunstwissenschaft und Kunstvermittlung [Theory of Art and Art Education], ed. Irene Below, 153-172. Gießen: Anabas.

Heinrich Dilly. 1996. Die Bildwerfer. 121 Jahre kunstwissenschaftlicher DiaProjektion [The Projector of Images. 121 Years of Scientific Diapositive Projektion]. In Im Bann der Medien. Texte zur virtuellen Ästhetik in Kunst und Kultur (CD-ROM) [The Curse of the Media. Texts about Virtual Aesthetics of the Art and Culture], ed. Kai-Uwe Henken, 134-164. Weimar: Ruhr-Universität Bochum.

Dyett, Marleen. 2013. Aus der Perspektive. Raster, Gitter, Netze: Betrachtungen zu einer Suggestion der Kunst. Würzburg: Königshausen \& Neumann.

Endres, Johannes, Wittmann, Barbara and Wolf, Gerhard, eds. 2005. Ikonologie des Zwischenraums. Der Schleier als Medium und Metapher [Iconology of the In-between, the Veil as Medium and Metaphor]. München: Fink.

Flückiger, Barbara. 2008. Visual Effects. Filmbilder aus dem Computer [Film Images from the Computer]. Marburg: Schüren Verlag. 
Greenberg, Clement. 1997. Die Essenz der Moderne. Ausgewählte Essays und Kritiken [The Essence of the Modernism. Selected Essays and Reviews]. Amsterdam, Dresden: Verlag der Kunst.

Jäger, Ludwig. 2004. Störung und Transparenz. Skizze zur performativen Logik des Medialen [Disturbance and Transparency. Sketches of the Perfomative Logic of Media]. In Performativität und Medialität [Performativity and Mediality], ed. Sybille Krämer, 35-74. München: Fink.

Krauss, Rosalind. 1981. Grilles. Communications no. 34: 167-176.

Luhmann, Niklas. 1987. Soziale Systeme: Grundriß einer allgemeinen Theorie [Social Systems: Foundations of a General Theory]. Frankfurt: Suhrkamp.

Luhmann, Niklas. 1995. Die Kunst der Gesellschaft [The Art of Society]. Frankfurt: Suhrkamp.

Mahr, Peter. 2003. Das Metaxy der Aisthesis. Aristoteles's 'de anima' als eine Ästhetik mit Bezug zu den Medien [The Metaxy of the Aisthetis. Aristoteles's 'de anima' as an Aesthetic with References to Media]. Wiener Jahrbuch für Philosophie vol. 25: 25-58.

McLuhan, Marshall. 1968. Die magischen Kanäle [Understanding Media]. Düsseldorf, Wien.

McLuhan, Marshall. 2003. Understanding Media: The Extensions of Man. London: Routledge.

Mitchell, W. J. T. 1990. Was ist ein Bild? [What is an Image?] In Bildlichkeit. Internationale Beiträge zur Poetik [Imageness. International Essays on Poetics], ed. Volker Nohn, 17-68. Frankfurt am Main: Suhrkamp.

Nelson, Robert. 2000. The Slide-Lecture, or The Work of Art "History" in the Age of Mechanical Reproduction. Critical Inquiry vol. 26 no 3 (Spring): 414-434.

Paech, Joachim. 2010. Übersetzung als intermediale Form [Translation as intermedial Form]. In Intermedien.Zurkulturellen und artistischen Übertragung [Intermedia. On Cultural and Artistic Translations], eds. Alexandra Kleihues, Barbara Naumann, Edgar Pankow, 489-504. Zürich: Chronos.

Wenk, Silke. 1999. Zeigen und Schweigen. Der kunsthistorische Diskurs und die Diaprojektion [Showing and Being Silent. The Art Historical Discourse in Diapositive Projections]. In Konfigurationen. Zwischen Kunst und Medien [Configurations. Between Art and Media], eds. Sigrid Schade and Georg Christoph Tholen, 292-305. München: Fink. 


\section{List of Figures}

Figures 1-2. Reproductions as 'images,' i.e. images of the original picture: Paul Klee's Scanty Words of the Thrifty Man (Karge Worte des Sparsamen, 1924). Left: Reproduction as a Poster. Right: Photograph taken from the original picture hanging on the wall in the museum.
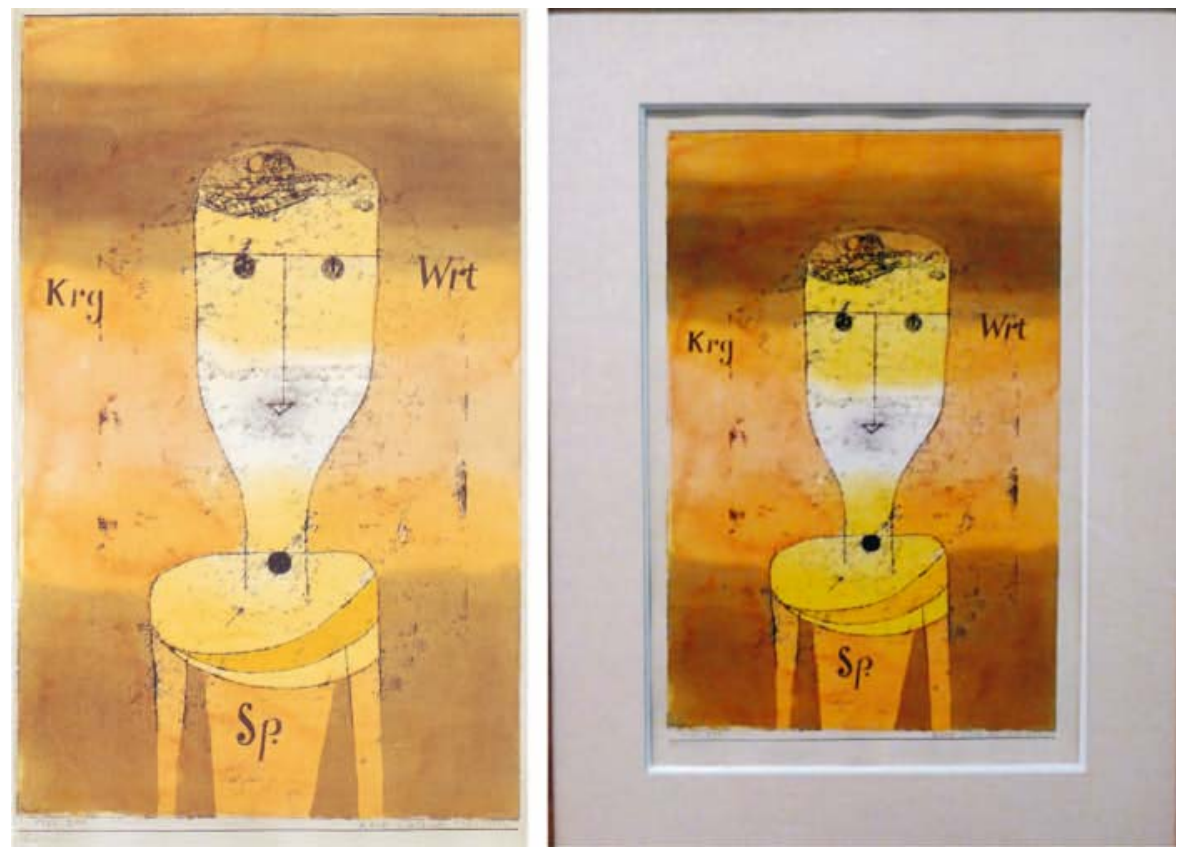

Figures 3-5. Example of the three phases of the zinc plate print.
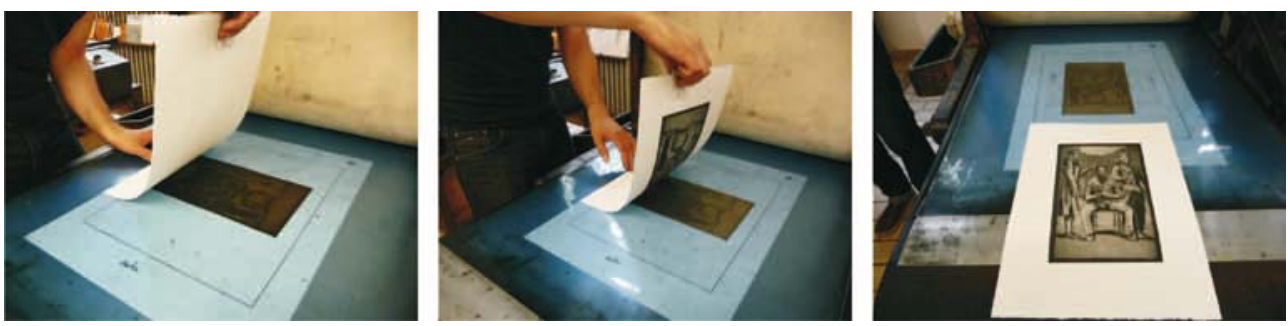
Figure 6. Albrecht Dürer: Unterweysung der Messung (Instruction in Measurement, 1538).

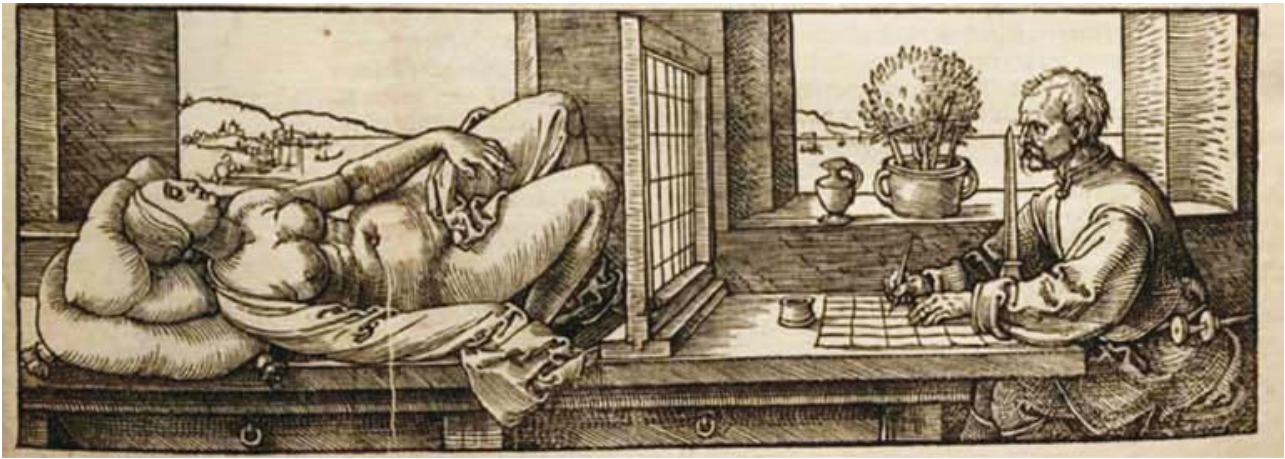

Figure 7. Construction of perspective: Masolino's St. Peter Healing a Cripple

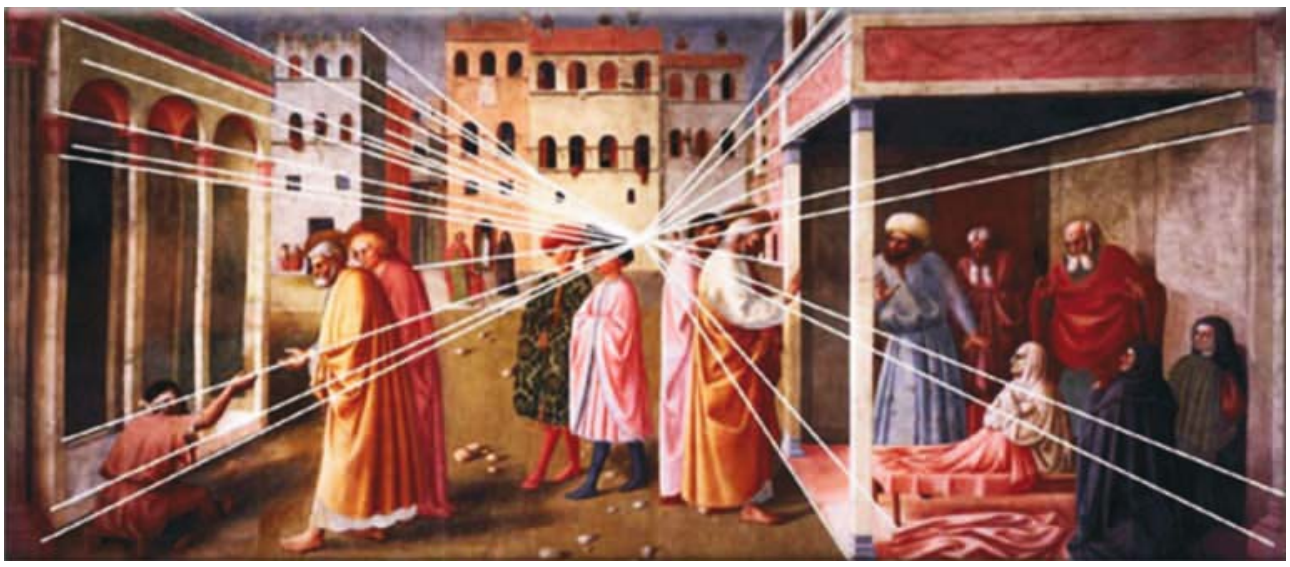

Figure 8. Film screening by the projection of single frames on top of each other.

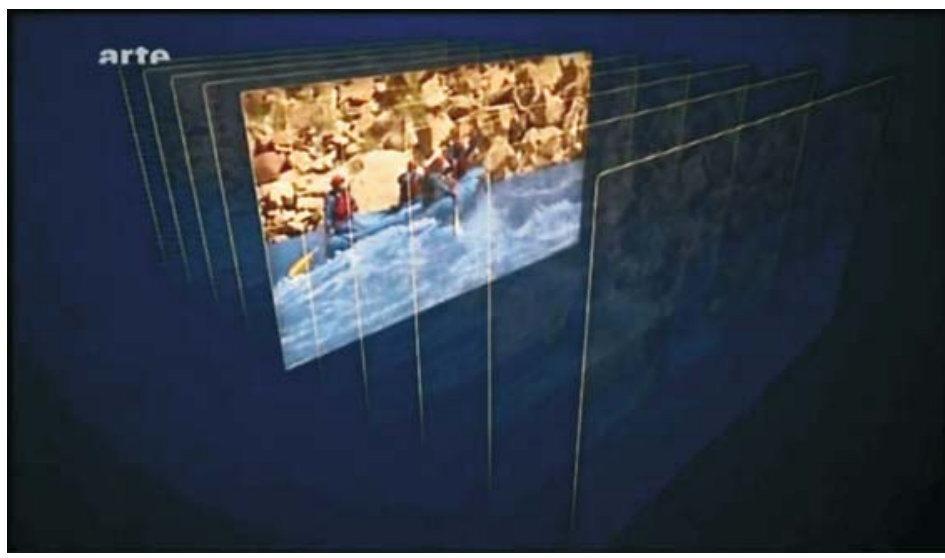


Figures 9-11. Roberto Rossellini: Chastity from ROGOPAG (1963).
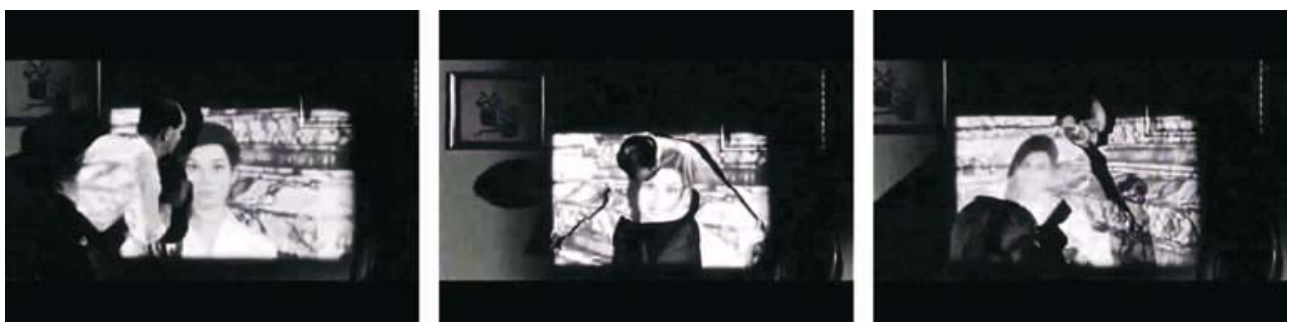

Figure 12. Particle Dreams (Karl Sims, 1988). Figure 13. Dürer's study of human proportions: faces under grids.
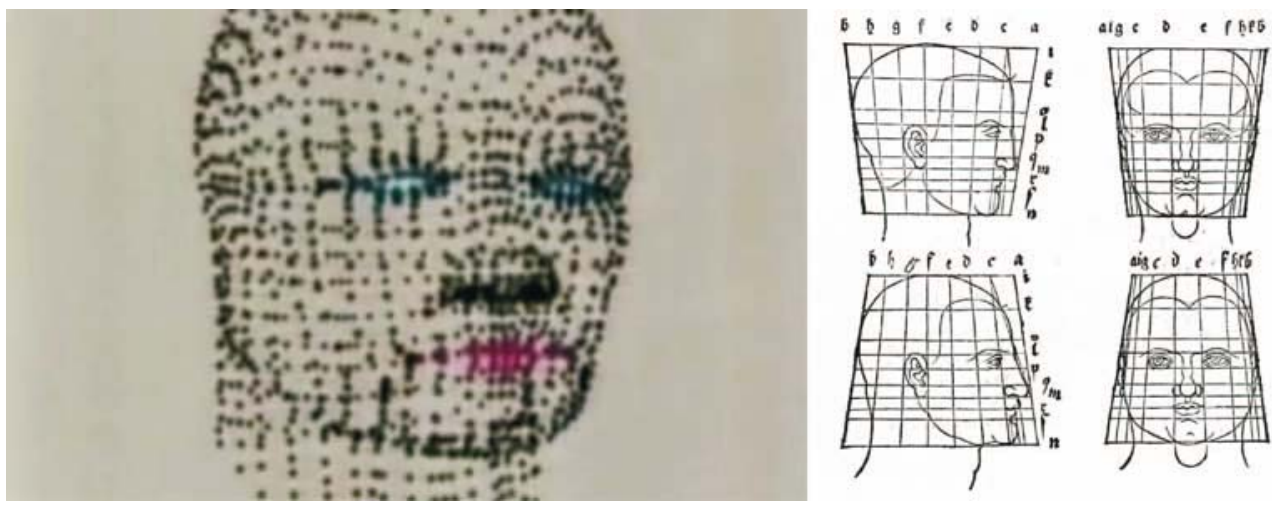